\title{
Nucleation of the electroactive phase of poly(vinylidene fluoride) by ferrite nanoparticles: surface versus size effects
}

\author{
P. Martins, C. M. Costa, M. Benelmekki, S. Lanceros-Mendez \\ Centro/Departamento de Física, Universidade do Minho, 4710-057 Braga, Portugal.
}

\begin{abstract}
Multiferroics and magnetoelectric materials show interesting scientific challenges and technnologial applications in sensors, acuators and data storage. In view of the fact that only a small number of materials show this kind of properties, exhaustive research activity is being pursued towards the development of new composite materials. Multiferroic nanocomposites films composed of piezoelectric poly(vinylidene fluoride) (PVDF) and magnetostrictive nanosize $\mathrm{CoFe}_{2} \mathrm{O}_{4}, \mathrm{NiFe}_{2} \mathrm{O}_{4}$ or $\mathrm{NiZnFe}_{2} \mathrm{O}_{4}$ ferrites were prepared by a solution method. Those ferrite nanoparticles have the ability to nucleate the electroactive $\beta$-phase of the polymer, providing in this way an easy route for the preparation of magnetoelectric particulate composites. The fact that the different nanoparticles promotes different amount of $\beta$-phase nucleation for different concentrations of nanoparticles indicates that filler size is not the most important parameter determining phase nucleation but the filler-matrix surface interaction. Further, when the polymer-ferrite surface interaction is modified through surfactation, the electroactive phase is not nucleated.
\end{abstract}

\section{INTRODUCTION}

The Magnetoelectric (ME) effect (induction of polarization by an applied magnetic field or induction of magnetization by an applied electric field) was first observed in singe phase materials (e.g. $\mathrm{Cr}_{2} \mathrm{O}_{3}$ ) [1], [2], [3]. Since the ME response of single phase materials is too weak for device applications, intensive studies were focused on the development of multiferroic composites combining piezoelectric and magnetostrictive materials [2], [4]. Multilayer and particulate piezoelectric/magnetostrictive films have been reported over the past few years [4], [5]. Laminated composites nevertheless are difficult to produce in large scale [5]. On the other hand, ceramic based composites are limited by deleterious reactions at the interface regions leading to low resistivities and high dielectric losses making such composites not suitable for device applications [6], [7].

One possible and efficient way to simplify the preparation process as well to avoid the problems of laminated and ceramic composites is to use polymer based composites with magnetostrictive particles. There composites are also promising candidates for outstanding magnetoelectric performance [8], [9].

PVDF is one of the most used piezoelectric polymer materials [10]. It shows five different crystalline phases known has $\alpha, \beta, \gamma, \delta$ and $\varepsilon$ that can be obtained depending on the processing conditions. The $\alpha$ and $\beta$ phases are the most important and also the most studied. The $\alpha$-phase is non-polar and it is obtained directly by cooling from the melt. The $\beta$-phase is the 
polymer phase with the highest piezoelectric, pyroelectric, and ferroelectric properties [10]. The polar $\beta$-phase is usually obtained by stretching $\alpha$-phase films at temperatures between $70^{\circ} \mathrm{C}$ and $100^{\circ} \mathrm{C}$ and stretch rations larger than four. Un-oriented $\beta$-phase films can be also obtained by crystallization from dimethyl formamide (DMF) or dimethyl acetamide (DMAc) solutions at temperatures below $70^{\circ} \mathrm{C}$, higher temperatures will usually result in a mixture of the $\alpha$ and $\beta$ phase, with the $\alpha$-phase fraction increasing with increasing temperatures [11], [12].

The preparation of the $\beta$-phase by stretchin from the $\alpha$-phase is not suitable for magnetoelectric composites once it will reduce the coupling between the polymer and the magnetostrictive phase.

Nano-size ferrites such as $\mathrm{CoFe}_{2} \mathrm{O}_{4}, \mathrm{NiFe}_{2} \mathrm{O}_{4}$ or $\mathrm{NiZnFe}_{2} \mathrm{O}_{4}$ can be incorporated into a poly(vinilidene fluoride), PVDF, matrix and have the ability to nucleate the electroactive beta phase of the polymer, providing in this way an easy route for the preparation of magnetoelectric particulate composites.

\section{EXPERIMENTAL}

$\mathrm{CoFe}_{2} \mathrm{O}_{4}, \mathrm{NiFe}_{2} \mathrm{O}_{4}$ and $\mathrm{NiZnFe}_{2} \mathrm{O}_{4}$ ferrite nanoparticles with dimensions between 35-55, 20-30 and 10-30 nm respectively were purchased from NanoAmor: Nanopowders \& Dispersions for Nanotechnology, Houston, USA. $N, N$-dimethylformamide (DMF, pure grade) and citric acid were supplied by Sigma-Aldrich, St. Louis, USA and PVDF was supplied by Solvay Solexis, Bollate, Italy. All the chemicals and nanoparticles were used as received from the suppliers.

Towards the preparation of the nanocomposites, two methods were applied to ensure a good dispersion of ferrite nanoparticles and to avoid loose aggregates:

a) the desired amount of nanoparticles were added to DMF and then placed in an ultrasound bath during 6 hours;

b) nanoparticles were surfactated with citric acid and later added to DMF [13].

Then, PVDF powder was added to the mixture of DMF and nanoparticles. The obtained blend was mixed in a Teflon mechanical stirrer for complete dissolution of the polymer powder during $1 \mathrm{~h}$. Samples with thickness of $\pm 50 \mu \mathrm{m}$ were obtained by spreading the solution on a very well clean glass substrate at room temperature. The thickness of the films was controlled by a spreader. Solvent evaporation was obtained inside an oven at a controlled temperature of $210^{\circ} \mathrm{C}$. After this step, samples were cooled down to room temperature. The weight percentage of ferrite nanoparticles varied from 0.001 to 50 . Fourier transform infrared spectroscopy (FTIR) has been proved to be suitable to identify and quantify phase content in PVDF [14]. Fourier transformed infrared spectroscopy (FTIR) spectra of the films were recorded on a Perkin-Elmer Spectrum 100 in ATR mode over a range of $650-1150 \mathrm{~cm}^{-1}$ with a resolution of $4 \mathrm{~cm}^{-1} .32$ scans were performed to each sample.

Scanning electron microscopy (SEM) measurements were performed in a FEI Nova NanoSEM 200 with an accelerating voltage of $20 \mathrm{kV}$, in previously gold coated samples (Polaron, model SC502 sputter coater). The samples analysed in cross-section were previously immersed in liquid nitrogen for $180 \mathrm{~s}$ in order to ensure that the sample temperature decreases below glass transition $(\mathrm{Tg})$, and then were mechanically broken. 
TGA was carried out to using Pyris 1 TGA - Perkin-Elmer under nitrogen atmosphere supplied at a constant $50 \mathrm{~mL} \mathrm{~min}^{-1}$ flow rate. The sample holders used were crucibles of ceramic with capacity of $60 \mu \mathrm{L}$. The samples were subjected to same heating rate of $10 \pm 0.2^{\circ} \mathrm{C} \cdot \mathrm{min}^{-1}$, between 50 and $850^{\circ} \mathrm{C}$, in order.

\section{DISCUSSION}

Figure 1 shows a representative SEM image of the samples with $20 \%$ of NiZn ferrite content prepared by ultrasound dispersion (a) and surfactated with citric acid (b).
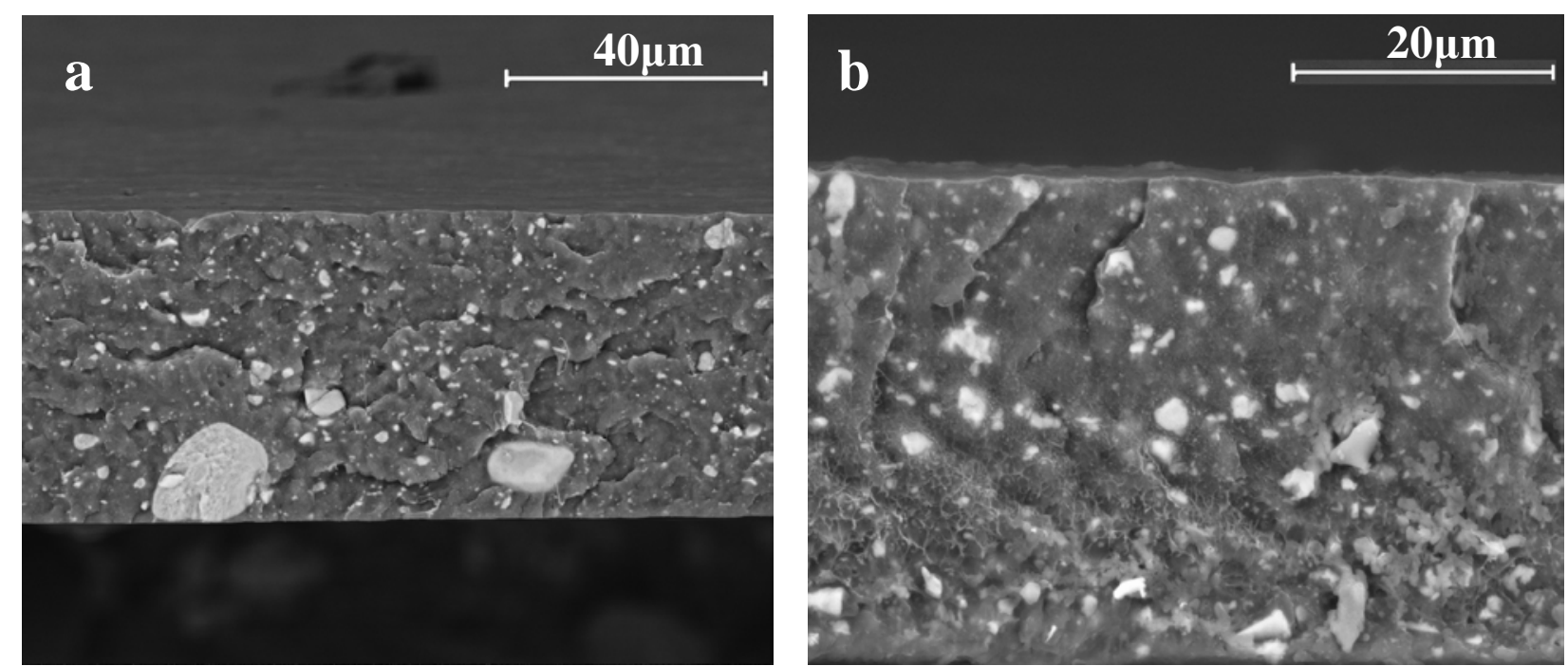

Figure 1 - SEM micrographs of NiZnFe2O4 nanocomposites with $20 \%$ of ferrite content: a) dispersed by ultrasound; b) using citric acid as surfactant

Agglomerates are observed in figure 1a. Due to the higher density of the ferrite agglomerates, they appear at the bottom of the samples, leading to a bad distribution of the ferrite particles along the composites. Some of the agglomerates have sizes of $30 \mu \mathrm{m}$ each, which difficult or even makes impossible the electric poling of the composites. On the other hand, citric acid surfactation of the samples lead to a homogeneous distribution of the ferrite nanoparticles by avoiding large agglomerates, $1 \mathrm{~b}$.

For the quantification of the polymer phase, specific bands such as 766 and $840 \mathrm{~cm}^{-1}$ have been identified to correspond to the $\alpha$ and $\beta$-phase respectively. The relative amount $\beta$ phase $(F(\beta))$ present in the samples was calculated applying equation 1 [15]:

$$
F(\beta)=\frac{X_{\beta}}{X_{\alpha}+X_{\beta}}=\frac{A_{\beta}}{\left(K_{\beta} / K_{\alpha}\right) A_{\alpha}+A_{\beta}}
$$

Here, $F(\beta)$ represents the $\beta$-phase content; $A_{\alpha}$ and $A_{\beta}$ the absorbencies at 766 and 840 $\mathrm{cm}^{-1}$, corresponding to the $\alpha$ and $\beta$ phase material; $K_{\alpha}$ and $K_{\beta}$ are the absorption coefficients at the respective wave number and $X_{\alpha}$ and $X_{\beta}$ the degree of crystallinity of each phase. The value of 
$K_{\alpha}$ is $6.1 \times 10^{4}$ and $K_{\beta}$ is $7.7 \times 10^{4} \mathrm{~cm}^{2} / \mathrm{mol}$. A similar procedure was used for the calculation of the $\beta$-phase content.
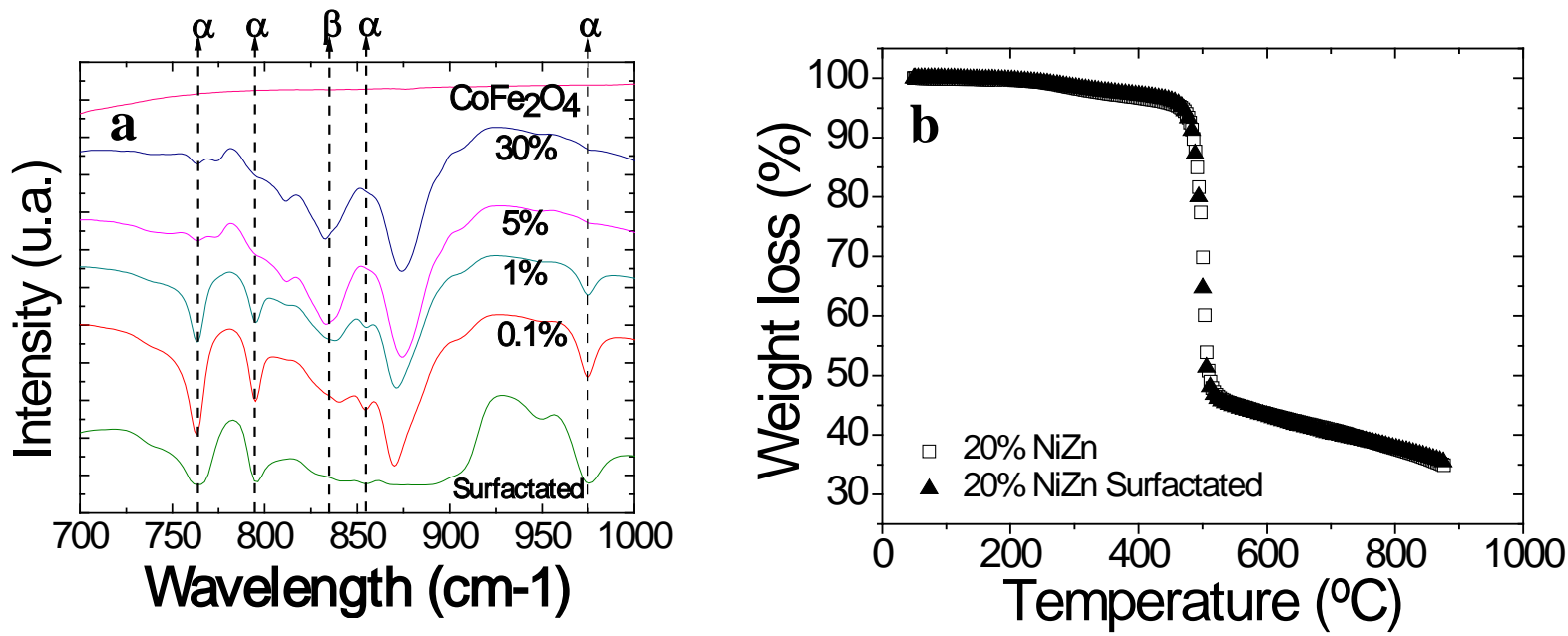

Figure 2 - a) Infrared measurements for the PVDF/CoFe2O4 composites samples $b$ ) Thermal degradation of $\mathrm{PVDF} / \mathrm{NiZnFe}_{2} \mathrm{O}_{4}(80 / 20 \mathrm{wt})$ composites obtained at $10^{\circ} \mathrm{C} \cdot \mathrm{min}^{-1}$ without and with surfactated nanoparticles.

The evolution of the $\alpha$ - and $\beta$ - phases for composites with increasing ferrite concentration is presented in Figure 2a and in Table1. The $\beta$-phase increases and correspondingly the $\alpha$-phase content decreases with increasing nanoparticle concentration.

Table 1. Phase content of all nanocomposites.

\begin{tabular}{|c|c|c|c|c|c|c|}
\hline Ferrite & \multicolumn{2}{|c|}{$\mathrm{CoFe}_{2} \mathrm{O}_{4}$} & \multicolumn{2}{|c|}{$\mathrm{NiFe}_{2} \mathrm{O}_{4}$} & \multicolumn{2}{|c|}{$\mathrm{NiZnFe}_{2} \mathrm{O}_{4}$} \\
\hline $\begin{array}{c}\text { Ferrite } \\
\text { Content } \\
(\%)\end{array}$ & $\begin{array}{c}\alpha \text { phase } \\
\text { content } \\
(\%)\end{array}$ & $\begin{array}{c}\beta \text { phase } \\
\text { content } \\
(\%)\end{array}$ & $\begin{array}{c}\alpha \text { phase } \\
\text { content } \\
(\%)\end{array}$ & $\begin{array}{c}\beta \text { phase } \\
\text { content } \\
(\%)\end{array}$ & $\begin{array}{c}\alpha \text { phase } \\
\text { content } \\
(\%)\end{array}$ & $\begin{array}{c}\beta \text { phase } \\
\text { content } \\
(\%)\end{array}$ \\
\hline 0.01 & 86.5 & 3,5 & 96.4 & 3,6 & 96 & 4 \\
\hline 0.1 & 83 & 7 & 96.8 & 3,2 & 95 & 5 \\
\hline 0.5 & 81 & 19 & 96.4 & 3.6 & 80 & 20 \\
\hline 1 & 67 & 23 & 96.6 & 3,4 & 70 & 30 \\
\hline 5 & 12.5 & 87,5 & 96.7 & 3,3 & 12.5 & 87.5 \\
\hline 10 & 13 & 87 & 93.3 & 6,7 & 13 & 87 \\
\hline 20 & 13.5 & 86,5 & 70 & 30 & 11.5 & 88.5 \\
\hline 30 & 13 & 87 & 44 & 56 & 12.3 & 87.7 \\
\hline 40 & 12.5 & 87,5 & 29 & 71 & 13 & 87 \\
\hline 50 & 12 & 88 & 16 & 84 & 21.1 & 87.9 \\
\hline
\end{tabular}


The fact that the $\beta$-phase of PVDF forms preferentially in this PVDF/ferrite nanocomposites indicates that the ferrite nanoparticles are nucleating $\beta$-phase epitaxially on their surfaces, this is supported by the FTIR spectra of the composites prepared from surfactated particles: modifying the surface properties of the particles improves dispersion but also hinders phase transformation resulting just in non-electroactive $\alpha$-phase composites (Figure 2a). Further there seems to be no particular relationship between the size of the particles and the concentration rate at which the $\beta$-phase is nucleated: the larger (Co) and smallest $\left(\mathrm{NiZn} \mathrm{Fe}_{2} \mathrm{O}_{4}\right)$ nucleate similar amounts of $\beta$-phase for similar concentrations.

Since the surface interactions between ferrite nanopaticles and the PVDF polymer induces the nucleation process of the $\beta$-phase, TGA was used to verify if the thermal stability and degradation of the composite is affected by the surfactation process. The TGA curves of the composites with and without citric acid surfactation are shown in Figure $2 \mathrm{~b}$. It is observed that two degradation mechanism occur, one around $250^{\circ} \mathrm{C}$ due to the presence of the nanoparticles (it does not exists for pure PVDF) [16] and the main degradation of PVDF at higher temperatures, that they are not affected by the surfactation process.

\section{CONCLUSIONS}

The nonfunctionalized ferrite nanoparticles used in this work nucleate the electroactive phase of PVDF, but at a different rate: whereas beta phase contents larger than $80 \%$ are obtained for $5 \%$ wt of $\mathrm{CoFe}_{2} \mathrm{O}_{4}$ and $\mathrm{NiZnFe}_{2} \mathrm{O}_{4}, 50 \%$ wt of $\mathrm{NiFe}_{2} \mathrm{O}_{4}$ is needed for obtaining those values of $\beta$-PVDF. This fact indicates that filler size is not the most important parameter determining phase nucleation but the filler-matrix surface interaction. These results do not support the theory of nanoparticles promoting phase nucleation when their radius is less than the radius of gyration, $\mathrm{R}_{\mathrm{g}}$ of the polymer [17]. The $\mathrm{R}_{\mathrm{g}}$ value for $\mathrm{PVDF}$ is $27,5 \mathrm{~nm}$, and the average radius of nanoparticles is $45 \mathrm{~nm}$ for $\mathrm{CoFe}_{2} \mathrm{O}_{4}, 25 \mathrm{~nm}$ for $\mathrm{NiFe}_{2} \mathrm{O}_{4}$ and $20 \mathrm{~nm}$ for. $\mathrm{NiZnFe}_{2} \mathrm{O}_{4}$. Nanoparticle funtionalization, i.e. modification of the polymer-ferrite surface interaction, on the other hand, promotes dispersion but prevents $\beta$-phase nucleation.

\section{ACKNOWLEDGMENTS}

The authors thank the Foundation for Science and Technology (FCT) through the $3^{\circ}$ Quadro Comunitario de Apoio, the POCTI and FEDER programs and the PTDC/CTM/69316/2006 and NANO/NMed-SD/0156/2007 projects. P. Martins thanks the support of the FCT (grant SFRH/BD/45265/2008)

\section{REFERENCES}

1. Mathur, N. D.et al, Multiferroic and magnetoelectric materials. Nature, 2006. 442 (7104): p. 759-765.

2. Spaldin, N. et al, The renaissance of magnetoelectric multiferroics. Science. 2005. 309 (573): p. 391-392.

3. Rado, G. et al, Observation of the Magnetically Induced Magnetoelectric Effect and 
Evidence for Antiferromagnetic Domains. Physical Review Letters,1961. 7(8): p. 310-311.

4. Nan, C. et al, Multiferroic magnetoelectric composites: Historical perspective, status, and future directions. Journal of Applied Physics, 2008. 103(3): p. 1-35.

5. Guo, Y. et al, Giant Magnetodielectric Effect in 0-3 Ni0.5Zn0.5Fe2O4-Poly(vinylidenefluoride) Nanocomposite Films. Journal of Physical Chemistry C, 2010. 114 (32): p. 1386113866 .

6. Li, Y et al, Magnetoelectric effect of Ni0.8Zn0.2Fe2O4/Sr0.5Ba0.5Nb2O6 composites. Journal of the European Ceramic Society, 2006. 26(13): p. 2839-2844.

7. Mitoseriu, L. et al, BaTiO3-(NiO.5ZnO.5)Fe2O4 ceramic composites with ferroelectric and magnetic properties. Journal of the European Ceramic Society, 2007. 27(13-15): p. 43794382.

8. Martins, $\mathrm{P}$ et al, Nucleation of electroactive $\beta$-phase poly(vinilidene fluoride) with CoFe2O4 and NiFe2O4 nanofillers: a new method for the preparation of multiferroic nanocomposites. Applied Physics A, Materials Science \& Processing, 2010. DOI: 10.1007/s00339-010-60037.

9. Zhang, Z. et al, The effect of magnetic nanoparticles on the morphology, ferroelectric, and magnetoelectric behaviors of CFO/P(VDF-TrFE) 0-3 nanocomposites. Journal of Applied Physics, 2009. 105(5): p. 1-6.

10. Fukada, E. et al, History and recent progress in piezoelectric polymers. IEEE Transactions on ultrasonics ferroelectrics and frequency control, 2000. 47(6) p. 1277-1290.

11. Branciforti, M. et al, New Technique of Processing Highly Oriented Poly(vinylidene fluoride) Films Exclusively in the $\beta$ Phase. Journal of polymer science Part B-Polymer Physics, 2007. 45(19): p. 2793-2801.

12. Martins, P. et al, Local variation of the dielectric properties of poly(vinylidene fluoride) during the alpha- to beta-phase transformation. Physics Letters A, 2009. 373(2): p. 177-180.

13. Campelj, S. et al, Preparation and properties of water-based magnetic fluids. Journal of Physics: Condensed Matter, 2008. 20(20): p. 1-5.

14. Kobayashi, $\mathrm{M}$ et al, Molecular Vibrations of Three Crystal Forms of Poly(vinylidene fluoride). Macromolecules, 1975. 8(2): p. 158-171.

15. Miranda, D. et al, Influence of Silver Nanoparticles Concentration on the alpha- to betaPhase Transformation and the Physical Properties of Silver Nanoparticles Doped Poly(vinylidene fluoride) Nanocomposites. Journal of nanoscience and nanotechnology, 2009. 9(5): p. 2910-2916.

16. Botelho, $\mathrm{G}$ et al, Relationship between processing conditions, defects and thermal degradation of poly(vinylidene fluoride) in the $\beta$-phase. Journal of non-crystalline solids, 2008, 354(1): p. 72-78.

17. Andrew, J. et al, Enhanced Ferroelectric Phase Content of Polyvinylidene Difluoride Fibers with the Addition of Magnetic Nanoparticles. Langmuir, 2008. 24(16): 8435-8438. 